\title{
Corrigendum
}

\section{Vaccinal approach using inactivated vaccine against heartwater and Ehrlichia ruminantium genetic diversity - CORRIGENDUM}

\author{
N. Vachiéry, Danièle Meyer, I. Marcelino, P. Alves, M. Raliniaina, F. Stachurski, H. Adakal, \\ C. Sheikboudou, R. Aprelon, V. Pinarello, T. Lefrançois and Dominique Martinez
}

doi:10.1017/S2040470010000178; published by Cambridge University Press, 8 November 2010

In the abstract by N. Vachiéry, Danièle Meyer, I. Marcelino, P. Alves, M. Raliniaina, F. Stachurski, H. Adakal, C. Sheikboudou, R. Aprelon, V. Pinarello, T. Lefrançois and Dominique Martinez (2010) presented in Advances in Animal Biosciences, the author names were listed incorrectly with the authors' given names and family names in the wrong sequence. The correct authorship is:

N. Vachiéry, D. Meyer, I. Marcelino, P. Alves, M. Raliniaina, F. Stachurski, H. Adakal, C. Sheikboudou, R. Aprelon, V. Pinarello, K. Giraud-Girard, T. Lefrançois and D. Martinez

The editors apologise to the authors and readers for this mistake.

\section{Reference}

Vachiéry N, Meyer D, Marcelino I, Alves P, Raliniaina M, Stachurski F, Adakal H, Sheikboudou C, Aprelon R, Pinarello V, Lefrançois T and Martinez D 2010. Vaccinal approach using inactivated vaccine against heartwater and Ehrlichia ruminantium genetic diversity. Advances in Animal Biosciences 1, 389-390. 